\title{
Human bioavailability of flavanols and phenolic acids from cocoa-nut creams enriched with free or microencapsulated cocoa polyphenols
}

\author{
Paola Vitaglione ${ }^{1 *}$, Roberta Barone Lumaga ${ }^{1}$, Rosalia Ferracane ${ }^{1}$, Sereno Sellitto ${ }^{1}$, José Ramón Morelló ${ }^{2}$, \\ Jordi Reguant Miranda ${ }^{2}$, Eyal Shimoni ${ }^{3}$ and Vincenzo Fogliano ${ }^{1}$ \\ ${ }^{1}$ Department of Food Science, University of Naples, via Università 100, Parco Gussone Ed. 84, Portici 80055, NA, Italy \\ ${ }^{2}$ La Morella Nuts, Reus, 43206 Tarragona, Spain \\ ${ }^{3}$ Technion - Israel Institute of Technology, Faculty of Biotechnology and Food Enginerring, IL-3200O Haifa, Israel
}

(Submitted 18 April 2012 - Final revision received 27 July 2012 - Accepted 1 August 2012 - First published online 10 October 2012)

\begin{abstract}
Human bioavailability of cocoa flavanols and phenolic acids from a cocoa-nut cream (CC) and from CC enriched with a $1.5 \%$ (w/w) cocoa polyphenol extract in free form (FPC) or encapsulated with a gastric-resistant high-amylose maize starch (EPC), was studied. In a randomised cross-over protocol, with 1-week wash-out in between, twelve healthy volunteers had three portions/d of each cream, providing approximately $190 \mu \mathrm{mol} / \mathrm{d}$ of total flavanols and $12 \mu \mathrm{mol} / \mathrm{d}$ of total phenolic acids with CC and 385 and $28 \mu \mathrm{mol} / \mathrm{d}$ with both FPC and EPC, respectively. Blood, urine and faecal samples were analysed by HPLC/MS/MS. Serum (epi)catechin was absent at baseline and after CC consumption, while 22.1 (SEM 2.62) and 1.59 (SEM 0.22) nmol $(P<0.05)$ were found after FPC and EPC, respectively. The EPC increased faecal excretion of total flavanols compared to FPC (151.0 (SEM 54.6) $v .28 .0$ (SEM 14.0) nmol; $P<0.05$ ). Within $6 \mathrm{~h}$ after consumption, serum phenolic acid content was 50-fold higher than (epi)catechin; no difference between CC and FPC was observed, but a significant reduction after EPC (1954 (SEM 236.3) and 1459 (SEM 137.6) $v .726 \cdot 8$ (SEM 73.4) nmol, $P<0.05)$ was recorded. Short-term phenolic acid urinary excretions were significantly higher after FPC than CC and EPC, the values being 11.4 (SEM 5.1) $v .3 \cdot 1$ (SEM $1 \cdot 7$ ) and 0.9 (SEM 0.5) $\mu \mathrm{mol}$, respectively. Faecal phenolic acids were approximately 60-fold reduced after FPC (8.1 (SEM 0.13) nmol) and EPC (14.7 (SEM 2.7) nmol) consumption compared to CC (641.4 (SEM 99.1) nmol) consumption. The data demonstrated that: (i) (epi)catechin was absorbed from CC; (ii) cocoa polyphenols' consumption increased circulating phenolic acids; and (iii) encapsulated ingredient increased flavanol delivering into the gut. Further studies should evaluate whether encapsulated cocoa polyphenols may be a functional prebiotic ingredient.
\end{abstract}

Key words: Bioavailability: Cocoa polyphenols: Encapsulation: Functional food

Epidemiological studies associate cocoa and chocolate consumption to a reduced risk of CVD, and attribute this effect to their polyphenol moiety ${ }^{(1,2)}$. Cocoa polyphenols include a sub-class of flavonoids, namely flavan-3-ols, occurring as monomers, mainly epicatechin and catechin, oligomers (procyanidins $\mathrm{B}_{1}, \mathrm{~B}_{2}$ and $\mathrm{C}_{1}$ ) and polymers (up to ten units), known as procyanidins ${ }^{(3-5)}$. Monomers account for $5-10 \%$ of total cocoa flavanols, while oligomers and polymers constitute $\geq 90 \%{ }^{(6)}$. They are the major cocoa polyphenols, being estimated to be more than $3 \mathrm{~g} / 100 \mathrm{~g}$ cocoa powder, while cocoa phenolic acids and flavonols are 100 times less abundant, estimated at $62 \mathrm{mg}$ and $30 \mathrm{mg} / 100 \mathrm{~g}$, respectively ${ }^{(7)}$. Small amounts of gallocatechin and epigallocatechin have also been quantified in cocoa $^{(5)}$. The abundance of flavanols compared to the other polyphenols has justified the major scientific interest shown up till now in the bioavailability of these compounds. All in all, bioavailability studies demonstrated that, whereas monomers are readily absorbed in the stomach and small intestine, the absorption of dimeric procyanidins in human subjects is very limited ${ }^{(8,9)}$. Indeed, polymeric procyanidins mainly reach the colon, where they are largely metabolised by the local micro-organisms to produce several phenolic acids ${ }^{(10-12)}$. Once formed, they are absorbed, further metabolised in the liver and excreted in urine ${ }^{(8,13,14)}$. Thus, the general consensus is that cocoa flavanol bioavailability is dependent on the ingested dose, the glucuronidated, sulphated and methylated metabolites being the most abundant compounds within $6 \mathrm{~h}$ after consumption, while phenolic acids (in the free forms or further metabolised by the liver) predominate later on. These in vivo studies were mainly

Abbreviations: CC, control cream; EPC, cream enriched with $1.5 \%$ (w/w) of the encapsulated cocoa polyphenol extract; FPC, cream enriched with $1.5 \%$ $(\mathrm{w} / \mathrm{w})$ of the free cocoa polyphenol extract; HACS, high-amylose maize starch. 
performed using chocolate or cocoa, consumed alone and/or with milk, and often highlighted some differences in bioaccessibility and biotransformation of cocoa polyphenols, depending on the composition of the dietary matrices such as the presence of proteins that generally retard polyphenol absorption as well as the fat content that may modulate relative absorption of individual compounds and/or metabolites ${ }^{(8,15-21)}$.

In some cases, the effects of cocoa or chocolate consumption were reported, a few hours after intake, on some markers of cardiovascular function (such as NO synthesis, flow-mediated vasodilation and peripheral arterial tonometry responses) and associated with the increased amount of catechin phase I/II metabolites in the blood ${ }^{(22)}$. However, the biological effects of flavanol-3-ol-conjugated metabolites have been mostly studied in vitro using concentrations that not always have physiological relevance; thus, the in vivo bioactivity of these compounds is still a highly debated matter ${ }^{(23)}$. On the other hand, the potential role of other classes of cocoa polyphenols, such as phenolic acids, in exerting short-term bioactive effects has never been explored, despite a growing interest in phenolic acids formed from the catabolism of flavanols by colon microflora emerging in the scientific literature ${ }^{(23)}$.

The knowledge of the relationship between the physiological response to foods and their composition is fundamental to formulate new ingredients and foods having a nutritional advantage, compared to the existing ones ${ }^{(24)}$. In general, due to the extensive metabolism and rapid excretion of cocoa flavanols, increasing their intake without increasing overall energy intakes may be nutritionally advantageous. Enrichment of cocoa-containing foods (e.g. chocolate bars, creams or drinks) with flavanol-rich extracts obtained from different cocoa bean fractions may be a reliable appropriate solution $^{(25)}$. Unfortunately, catechin and procyanidin enrichment over a certain level may impart an undesired bitter and astringent taste to the final product. Encapsulation of cocoa polyphenol extract may overcome this limitation. In fact, during the last 10 years, this technology has rapidly enlarged its application in the food industry, thus allowing food addition with several bioactive compounds, guaranteeing their protection during food processing, tailoring their release over time and/or at particular sites and masking unwanted tastes and flavours of core materials ${ }^{(26-28)}$.

In this framework, the objectives of the present study were to evaluate human bioavailability of cocoa flavanols and phenolic acids upon consumption of nut creams containing $20 \%$ of cocoa (CC) and to evaluate whether, and to what extent, cocoa-nut cream enrichment with a cocoa polyphenol extract in free (FPC) or in encapsulated (EPC) form influenced this issue. For this purpose, nut creams were developed and produced. A total of twelve healthy volunteers participated in the study, consumed the creams in a randomised manner and blood, urine and faeces were collected at specific time points over $24 \mathrm{~h}$. Biological samples were analysed by HPLC/MS/MS to monitor free native flavanol-3-ols (monomers and dimers) and several phenolic acids (both present in cocoa-nut creams as well as known to originate from cocoa flavanols and flavonols).

\section{Materials and methods}

\section{Chemicals and reagents}

All chemicals and reagents were of analytical grade. Methanol, water, acetonitrile and hexane were from Merck; only for cream chemical characterisation, water was obtained from a MilliQ water purification system (Millipore Corporation). Ethyl acetate, glacial acetic acid and $\mathrm{HCl}$ were from Clean Consult International; formic acid (98\% purity), butylated hydroxytoluene and salts used for PBS preparation were obtained from Sigma. All analytical standards, 5-caffeoylquinic acid (95\%, chlorogenic acid), trans-4-hydroxy-3-methoxycinnamic acid (99\%, ferulic acid), 3,4-dihydroxybenzoic acid ( $\geq 97 \%$, protocatechuic acid), 4-hydroxybenzoic acid (99\%, $p$-hydroxybenzoic acid), 3,4-dihydroxycinnamic acid ( $\geq 98 \%$, caffeic acid), 4-hydroxyphenylacetic acid (98\%), 3-(4-hydroxyphenyl)propionic acid (98\%), 4-hydroxy-3-methoxybenzoic acid (97\%, vanillic acid), naringenin (98\%) and quercetin ( $\geq 98 \%)$ were purchased from Sigma. (+)-Catechin ( $\geq 99 \%)$, $(-)$-epicatechin $(\geq 97 \%)$, procyanidin $\mathrm{B}_{1}$ and $\mathrm{B}_{2}(\geq 90 \%)$, apigenin $(\geq 99 \%)$, luteolin $(\geq 97 \%)$ and kaempferol $(\geq 99 \%)$ were obtained from Fluka.

\section{Preparation of free and encapsulated cocoa polyphenol extract}

Polyphenol extract from cocoa nibs was produced by La Morella Nut, according to the procedure described by Ortega et al. ${ }^{(25)}$. It was partly microencapsulated by KARMAT using a technological process based on the formation of nanocomplexes with a high-amylose maize starch (HACS) as coating agent of cocoa polyphenols and on their aggregation in microcomplexes. In particular, the following steps were performed: (1) solubilisation of the coating material in an alkaline solution ( $\mathrm{pH} 12)$ kept at high temperature $\left(80^{\circ} \mathrm{C}\right)$ and stirred continuously; (2) chilling this material up to $30^{\circ} \mathrm{C}$; (3) addition, under stirring, of the cocoa extract up to $10 \%$ of HACS (w/w); (4) pressurisation into an homogenator together with an acid solution until a $\mathrm{pH}$ of approximately 5 is reached and, finally, spray-drying using $200^{\circ} \mathrm{C}$ as inlet temperature, approximately $100^{\circ} \mathrm{C}$ outlet temperature and a flow rate of $10 \mathrm{l} / \mathrm{h}$ to obtain fine particles.

The final ingredient contained cocoa polyphenol extractHACS in a 1:9 $(\mathrm{w} / \mathrm{w})$ ratio.

\section{Preparation of cocoa-nut creams}

Once the polyphenol-rich ingredients were obtained, a nut cream containing $20 \%(\mathrm{w} / \mathrm{w})$ cocoa (control cream, CC) and ten prototypes of polyphenol-enriched cocoa-nut creams containing free or encapsulated polyphenols ranging from 0.5 to $2.5 \%(\mathrm{w} / \mathrm{w})$ were prepared by a pilot-scale apparatus located at La Morella Nuts. The CC was prepared by the sequential addition of individual ingredients through continued mixing, in order to obtain a well-mixed and refined cream (particle sizes about $30 \mu \mathrm{m}$ ). To this basic cream, the free or encapsulated polyphenol extract was slowly added and mixed gently to homogenously disperse the ingredients. 
Once the homogeneous products were obtained, creams were immediately packaged in 33-g portions and labelled with alpha-numeric codes.

\section{Sensory analysis of creams}

To establish what was the maximum enrichment of the creams achievable with the polyphenol-rich ingredients, a sensory analysis of the ten cream prototypes was performed. A total of thirty untrained subjects, selected among students and staff of the Department of Food Science at the University of Naples based on medical status, absence of allergies and habitual consumption of nut/chocolate creams and spreads, were enrolled to participate in the study. The selected subjects were healthy, of both sexes (fifteen male and fifteen female), between 25 and 35 years of age and were of normal weight (BMI 22 (SEM 2) $\mathrm{kg} / \mathrm{m}^{2}$ ). A total of ten prototype formulations, prepared as described earlier, were compared to CC: they contained $0.5,1,1.5,2$ and $2.5 \%$ of the cocoa polyphenol extract, in free or encapsulated form. At different days for each test, and always at least $2 \mathrm{~h}$ after having breakfast, three types of creams were tested in blinded and randomised manner. Approximately $10 \mathrm{~g}$ of each cream, placed in transparent small cups, were provided to subjects together with a glass of room temperature water and a slice of white bread for palate cleansing between sample testing. The panelists were asked to taste and to assign a score to their hedonic of the following sensory attributes: sweetness, bitterness, creaminess, fatness, granularity and overall palatability. Ratings were based on a nine-point hedonic scale $(0=$ extremely dislike, $9=$ extremely like).

\section{Composition of the cocoa-nut creams}

The composition of CC, FPC and EPC is summarised in Table 1 , reporting for each parameter the mean of three measures obtained by triplicate analysis and sEm. Water, lipids, proteins and carbohydrates were determined by official methods of analysis (AOAC 9321.04, AOAC 963.15, AOAC 939.02, AOAC 980.13, respectively), while flavanols (monomers, oligomers and polymers) as well as phenolic acids and flavonols were measured according to the method described by Ortega et al. ${ }^{(25)}$ with slight modifications. Briefly, approximately $3 \mathrm{~g}$ of sample were weighted and fat was removed by using $3 \mathrm{ml}$ of hexane. Polyphenols were extracted from the defatted pellet using a total volume of $9 \mathrm{ml}(3 \times 3 \mathrm{ml})$ acetone-water (1:1) solution. After addition of extraction solvent to the pellet, the whole mixture was sonicated for $10 \mathrm{~min}$ at $4^{\circ} \mathrm{C}$ to improve the polyphenols' extraction efficiency and obtain a recovery of $98 \%$ of polyphenols from the encapsulated ingredient (as found in preliminary experiments whose data are not shown). All acetone/water phases were collected and acetone removal by rotary evaporator was followed by freeze-drying of resulting aqueous solutions. Finally, approximately $10 \mathrm{mg}$ of dried extracts were suspended in $2 \mathrm{ml}$ of a methanolwater (1:1) solution and $20 \mu$ l of this suspension were injected in to a HPLC system (Shimadzu LC-10A Series) equipped with two pumps (LC-10AD), a controller (SCL-10A) and a diodearray detector (SPD-M10A). Chromatography separation was carried out with a Prodigy $5 \mu \mathrm{m}$ ODS- $3100 \AA$ column, size $250 \times 4.60 \mathrm{~mm}$ C18 column, purchased from Phenomenex, with a mobile phase flow rate of $0.8 \mathrm{ml} / \mathrm{min}$, consisting of acidified water with $0.2 \%$ of formic acid (phase A) and an acetonitrile-methanol solution in the ratio $60: 40(\mathrm{v} / \mathrm{v}$, phase $\mathrm{B})$. The elution gradient was set as follows: time $0=20 \% \mathrm{~B} ; 0-6 \min 30 \% \mathrm{~B} ; 6-16 \min 40 \% \mathrm{~B} ; 16-24 \mathrm{~min}$ $50 \% \mathrm{~B} ; 24-32 \mathrm{~min} 98 \% \mathrm{~B} ; 32-35 \mathrm{~min} 98 \% \mathrm{~B} ; 35-40 \mathrm{~min}$ $20 \% \mathrm{~B}$; and $40-45 \mathrm{~min} 20 \% \mathrm{~B}$. Catechin, epicatechin, procyanidin $\mathrm{B}_{2}, p$-hydroxybenzoic acid, vanillic acid, apigenin, naringenin, quercetin arabinoside, luteolin glucoside, quercetin glucoside and kampferol-rutinoside were detected at $280 \mathrm{~nm}$; protocatechuic acid at $254 \mathrm{~nm}$; and chlorogenic acid,

Table 1. Composition of experimental creams (per $100 \mathrm{~g}$ )

(Mean values with their standard errors $(n 3)$ )

\begin{tabular}{|c|c|c|c|c|c|c|}
\hline & \multicolumn{2}{|c|}{$\mathrm{CC}$} & \multicolumn{2}{|c|}{ FPC } & \multicolumn{2}{|c|}{ EPC } \\
\hline & Mean & $\overline{S E M}$ & Mean & $\overline{\text { SEM }}$ & Mean & SEM \\
\hline Water (g) & 1.5 & 0.1 & 1.5 & 0.1 & $1 \cdot 3$ & 0.2 \\
\hline Protein (g) & $7 \cdot 9$ & 0.3 & $7 \cdot 8$ & 0.6 & $6 \cdot 7$ & 0.5 \\
\hline Carbohydrates (g) & $49 \cdot 7$ & $2 \cdot 1$ & $50 \cdot 0$ & 1.8 & $57 \cdot 3^{\star}$ & $2 \cdot 8$ \\
\hline Dietary fibre & $40 \cdot 0$ & 3.0 & $40 \cdot 1$ & $2 \cdot 6$ & $47 \cdot 2^{*}$ & $2 \cdot 0$ \\
\hline Lipids (g) & $40 \cdot 9$ & 2.9 & $40 \cdot 8$ & $3 \cdot 1$ & 34.8 & 1.9 \\
\hline Total flavanols $(\mu \mathrm{mol})$ & $190 \cdot 0$ & $2 \cdot 2$ & $385 \cdot 1 \dagger$ & $5 \cdot 3$ & $385 \cdot 3 \dagger$ & 4.9 \\
\hline Monomersł & $176 \cdot 0$ & $2 \cdot 1$ & $336 \cdot 8 \dagger$ & $5 \cdot 0$ & $337.0 \dagger$ & 4.4 \\
\hline Dimers§ & $14 \cdot 0$ & 0.1 & $48.3 \dagger$ & 0.3 & $48.3 \dagger$ & 0.5 \\
\hline Total phenolic acids $(\mu \mathrm{mol}) \|$ & $12 \cdot 0$ & 0.9 & $28 \cdot 1 \dagger$ & $1 \cdot 0$ & $27 \cdot 9 \dagger$ & 0.2 \\
\hline Total flavonols $(\mu \mathrm{mol}) \uparrow$ & $9 \cdot 2$ & 0.0 & $12.9 \dagger$ & 0.1 & $13.0 \dagger$ & 0.4 \\
\hline
\end{tabular}

CC, control cream; FPC, cream enriched with $1.5 \%(\mathrm{w} / \mathrm{w})$ of the free cocoa polyphenol extract; EPC, cream enriched with $1.5 \%(\mathrm{w} / \mathrm{w})$ of the encapsulated cocoa polyphenol extract. ${ }^{*}$ Mean values were significantly different from that of FPC $(P<0.05$; Bonferroni test). † Mean values were significantly different from that of $C C(P<0.05$; Bonferroni test). $\ddagger$ Catechin and epicatechin. $\S$ Procyanidin $\mathrm{B}_{1}$ and $\mathrm{B}_{2}$.

$\| p$-Hydroxybenzoic acid, vanillic acid, protocatechuic acid, chlorogenic acid and caffeic acid

ๆ Apigenin, naringenin, quercetin arabinoside, luteolin glucoside, quercetin glucoside, kampferol-rutinoside and rutin. 
caffeic acid and rutin at $330 \mathrm{~nm}$. The peak area was integrated by means of Class-VP software (version 7.3) obtained from Shimadzu. Each compound was quantified using specific calibration curves obtained with the reference standard compounds, as reported previously; for glycosides, the calibration curves of the respective aglycones were used.

\section{Bioavailability study}

Study design. The present study was a single-blind study, and had a randomised, cross-over design with three arms.

The present study was conducted according to the guidelines laid down in the Declaration of Helsinki, and all procedures involving subjects were approved by the Ethics Committee of 'Federico II' University of Naples (Ethic Approval Number 37/10). Written informed consent was obtained from all subjects before entering into the study.

A total of twelve healthy volunteers (four males/eight females, mean age 24 (sem 3) years, BMI $23 \cdot 1$ (sem 1.5$) \mathrm{kg} / \mathrm{m}^{2}$ ) were selected among the students of the Agricultural Faculty, University of Naples. Subjects reporting symptoms of gastrointestinal disorders (including frequent diarrhoea episodes or constipation), having metabolic diseases (diabetes, metabolic syndrome, etc.), taking non-steroidal anti-inflammatory drugs or having undergone controlled dietary regimens over the last 6 months were considered ineligible for the present study. The selected volunteers signed a written informed consent before starting the study. The experimental design is schematised in Fig. 2. For the $3 \mathrm{~d}$ before and over each experiment day, subjects were asked to follow a polyphenolfree diet. It consisted, in exclusion of the habitual diet, of all polyphenol-rich foods and beverages such as fruits, vegetables, chocolate, tea, coffee, wine, beer, supplements, herbal extracts and wholegrain-based foods. Consumption of non-steroidal anti-inflammatory drugs and antibiotics was also avoided during 1 week and 1 month before treatments, respectively. On the experiment day, after fasting for $12 \mathrm{~h}$, the subjects reached the laboratory at 08.00 hours and were randomised to receive one of the three experimental creams, which was consumed within $15 \mathrm{~min}$ together with three slices of toasted bread and a glass of room temperature water. They left the research centre $6 \mathrm{~h}$ later and were allowed to have lunch (within 14.45 hours) and dinner (within 22.00 hours), including, in both occasions, another cream portion. Each subject was invited to consume lunch and dinner during the three experimental sessions, always constituting the same foods, so that no influence of dietary pattern on bioavailability of compounds in the three treatments might occur. In particular, they were invited to choose among the following foods: rice or pasta with butter and cheese or with tuna, meat or fish or bread with ham and/or cheese. After $24 \mathrm{~h}$, subjects returned to consume their own habitual diet for a 1-week wash-out period. After this week, the experimental design was repeated. In particular, subjects again followed a 3-d polyphenol-free diet and were randomised for another treatment.

Thus, all subjects participated in the three experimental sessions (one for each type of cream) with a 1-week interval between each other, and on each test day, they consumed three portions $(99 \mathrm{~g})$ of the test cream they were randomised for.

Sample collection. At fasting conditions and at $30 \mathrm{~min}$, 1, 2, 4 and $6 \mathrm{~h}$ after breakfast consumption, blood samples were drawn. Then, $24 \mathrm{~h}$ urine was collected over $0-2,2-4$, $4-6,6-8,8-10,10-24 \mathrm{~h}$ time intervals, after ingestion of the first cream portion, and the volume was measured. The $10 \mathrm{ml}$ samples of urine collected before breakfast and at each time interval were stored for analysis. The day after the experiment, participants returned to the laboratory after fasting for $12 \mathrm{~h}$ and their blood samples were taken $(24 \mathrm{~h}$ from the first cream consumption), while the faecal sample was collected on the experiment day. No subject was constipated or had diarrhoea episodes over the study period; thus, faecal samples were always collected from each volunteer.

Biological sample treatment, storage and analysis. Blood samples were collected in a Vacutainer tube for gel separation, and immediately centrifuged at $4000 \mathrm{rpm}$ for $10 \mathrm{~min}$ at $4^{\circ} \mathrm{C}$. Urine samples were immediately treated with $0.005 \%$ of butylated hydroxytoluene. Faeces were diluted in the ratio 1:10 $(\mathrm{w} / \mathrm{v})$ in PBS (10 mm) containing $0.005 \%$ of butylated hydroxytoluene, vortexed and centrifuged at $4000 \mathrm{rpm}$ for $15 \mathrm{~min}$ at $4^{\circ} \mathrm{C}$. Serum, urine and faecal supernatants were stored at $-40^{\circ} \mathrm{C}$ until the analysis. Procyanidins, metabolites and phenolic acids were extracted by $1.5 \mathrm{ml}$ of ethyl acetate from $500 \mu \mathrm{l}$ of serum and $1.5 \mathrm{ml}$ of urine and faecal suspensions (twice and for three times, respectively). The collected supernatants were dried under nitrogen flow and the dry extracts were dissolved in $50 \mu \mathrm{l}$ methanol-water (70:30); $30 \mu \mathrm{l}$ were injected into HPLC/MS/MS apparatus. Each sample was extracted in duplicates. Quantitative determination of total extracted analytics was performed using a HPLC system consisting of two micropumps by Perkin Elmer Series 200, coupled with an API 3000 Triple Quadrupole mass spectrometer (Applied Biosystem Sciex). Elution was achieved with a Phenomenex Luna $3 \mu \mathrm{C} 18(2) 100 \mathrm{~A}(50 \times 2.00 \mathrm{~mm})$ column and by using the following mobile phases: $\mathrm{A}=$ water-acetonitrile-formic acid 94.9:5:0·1 (by vol.) and $\mathrm{B}=$ acetonitrile-formic acid 99.9:0 $1(\mathrm{v} / \mathrm{v})$; the flow rate was $200 \mu \mathrm{l} / \mathrm{min}$. The linear gradient for chromatographic separation was: $0-1 \mathrm{~min}, \quad 4-40 \% \mathrm{~B} ; 1-3 \mathrm{~min}, \quad 40-100 \% \mathrm{~B}$; 3-5 min, $100 \% \mathrm{~B}$; and 6-10 min, 4\% B. Selected compounds in the native form were detected and quantified through electrospray ionisation MS/MS analysis. After ionisation in negative mode, transitions of parent and product ions specific for each compound were tracked in multiple reaction monitoring mode. For each compound, all MS parameters (declustering potential, focusing potential, collision energy, collision cell exit potential), set as previously described ${ }^{(12,29)}$ and then optimised through direct infusion experiments, are reported in Table 2, together with limits of detection and quantification. When analytical standards were not available, compounds were identified comparing molecular weight and fragmentation patterns with those reported in the literature ${ }^{(12,29)}$. Epigallocatechin was quantified using the calibration curve built with epicatechin; hippuric, dihydroferulic and hydroxybenzoic acids were quantified using the calibration curve built 
Table 2. MS parameters, negative ions and transition product ions analysed by HPLC/MS/MS

\begin{tabular}{|c|c|c|c|c|c|c|c|c|c|}
\hline \multirow[b]{2}{*}{ Compound } & \multirow[b]{2}{*}{$\mathrm{M}-\mathrm{H}$} & \multirow[b]{2}{*}{ Product ions } & \multirow[b]{2}{*}{$\mathrm{DP}$} & \multirow[b]{2}{*}{$\mathrm{FP}$} & \multirow[b]{2}{*}{ CE } & \multicolumn{2}{|c|}{ CXP } & \multirow[b]{2}{*}{ LOD $(\mathrm{ng} / \mathrm{ml})$} & \multirow[b]{2}{*}{$\mathrm{LOQ}(\mathrm{ng} / \mathrm{ml})$} \\
\hline & & & & & & 1 & 2 & & \\
\hline Procyanidin $\mathrm{B}_{2}$ & 577 & $289 ; 425 ; 407$ & -45 & -300 & $-35 ;-25 ;-31$ & -7 & & 2.5 & $5 \cdot 0$ \\
\hline (Epi)catechin & 289 & 245 & -40 & -300 & -21 & -7 & & $5 \cdot 0$ & $10 \cdot 0$ \\
\hline $\mathrm{EGC}^{*} \dagger$ & 305 & 179 & -40 & -375 & -30 & -7 & & - & - \\
\hline Protocatechuic acid & 153 & 109 & -45 & -400 & -21 & -10 & & 0.5 & 1.0 \\
\hline Vanillic acid & 167 & $152 ; 108 ; 123$ & -45 & -250 & $-22 ;-26$ & -9 & -11 & 2.5 & $5 \cdot 0$ \\
\hline Ferulic acid & $192 \cdot 8$ & $133.9 ; 177.9$ & -35 & -250 & $-22 ;-17$ & -10 & & 0.5 & 1.0 \\
\hline Chlorogenic acid & 353 & 191 & -35 & -250 & -21 & -8 & & 0.5 & 1.0 \\
\hline Caffeic acid & 179 & 135 & -49 & -350 & -35 & -8 & & 0.5 & 1.0 \\
\hline Hippuric acid* $\ddagger$ & 178 & $134 ; 77$ & -45 & -350 & -20 & -7 & & - & - \\
\hline Homovanillic acid & $180 \cdot 8$ & $136 \cdot 7 ; 122$ & -50 & -350 & $-10 ;-18$ & -7 & & $25 \cdot 0$ & $100 \cdot 0$ \\
\hline Hydroxybenzoic acid $\ddagger$ & 137 & 93 & -50 & -350 & -25 & -7 & & - & - \\
\hline Coumaric acid & 163 & $119 \cdot 1$ & -40 & -350 & -23 & -5 & & 2.5 & $5 \cdot 0$ \\
\hline Di-HCA & $181 \cdot 1$ & $109 ; 137$ & -50 & -300 & $-25 ;-14$ & -9 & & 25 & 50 \\
\hline Di-HFA* $\ddagger$ & 195 & 136 & -40 & -350 & -20 & -6 & & - & - \\
\hline DHPA & 167 & 123.1 & -30 & -250 & -11 & -7 & & 0.5 & 1.0 \\
\hline HPA & 151 & $107 ; 78.9$ & -35 & -250 & $-16 ;-25$ & -7 & & 3.0 & $5 \cdot 0$ \\
\hline HPP & 164.9 & $121 ; 105.9 ; 76.7$ & -25 & -250 & $-10 ;-20 ;-10$ & -7 & & $25 \cdot 0$ & $100 \cdot 0$ \\
\hline $\mathrm{DHPV}^{*} \S$ & 207 & $163 ; 122$ & -35 & -350 & -25 & -7 & & - & - \\
\hline
\end{tabular}

CXP, collision cell exit potential; DP, declustering potential; FP, focusing potential; CE, collision energy; LOD, limit of detection; LOQ, limit of quantification; EGC, epigallocatechin; Di-HCA, dihydrocaffeic acid; Di-HFA, dihydroferulic acid; DHPA, 3,4-dihydroxyphenylacetic acid; HPA, 4-hydroxyphenylacetic acid; HPP, 3-(4-hydroxyphenyl)propionic acid; DHPV, 5-(3', $4^{\prime}$-dihydroxyphenyl)- $\gamma$-valerolactone.

* Identified based on molecular weight and specific fragmentation patterns, as reported by Fogliano et al. ${ }^{(12)}$ and Urpi-Sarda et al. ${ }^{(29)}$.

† Reference calibration curve was epicatechin.

$\ddagger$ Reference calibration curve was ferulic acid

$\S$ Reference calibration curve was HPA.

with ferulic acid; and dihydroxyphenyl- $\boldsymbol{\gamma}$-valerolactone was quantified using the calibration curve built with hydroxyphenylacetic acid.

\section{Statistical analysis}

Statistical analysis was performed using the statistical package SPSS for Windows (version 15; SPSS Inc.). The results from HPLC/MS/MS analysis were analysed and expressed as the absolute changes from the baseline to reduce possible effects of inter-subject fasting variability. The AUC for each compound from baseline to $6 \mathrm{~h}$ after first cream portion consumption in the case of serum samples and to $0-6$ and $6-24 \mathrm{~h}$ for urine samples were estimated using the linear trapezoidal rule. As data were normally distributed and presented homogeneous variance (Levene test), they were analysed by oneway ANOVA for repeated measures; the subjective time curves for all measured compounds were compared and tested for the effect of treatment and of time as factors. For all tests, following a significant main effect in the ANOVA, individual means were compared using the Bonferroni test $(P<0 \cdot 05)$. Results were considered significant at $P<0.05$. All values were reported as means with their standard errors.

\section{Results}

\section{Sensory analysis of creams}

The products enriched with 2 and $2.5 \%(\mathrm{w} / \mathrm{w})$ of polyphenol extracts obtained an overall acceptability score of 4.6 (SEM 1.3) and 4.6 (SEM 1.1) (2.0\% polyphenols) and 4.12 (SEM 1.0) and 4.2 (SEM 1.2) (2.5\% polyphenols) for free cocoa polyphenol and encapsulated extract, respectively. These low scores, compared to the one attributed to the CC (7.5 (SEM 1.3)), were conditioned by the bitterness perception for the creams enriched with 2.0 and $2.5 \%$ of the free extract (3.5 (SEM 1.2) and $2 \cdot 9$ (SEM $1 \cdot 3$ ), respectively) and the granularity for those containing the same amounts of encapsulated extract (3.7 (SEM 1.2) and 3.0 (SEM 1.3), respectively). The 1.5\%-enriched creams obtained a mean score for total acceptability of approximately $6.5(6.4$ (SEM 1.3$)$ and 6.6 (SEM 1.2 ), when contained free cocoa polyphenol or encapsulated cocoa polyphenol extract, respectively), while hedonic for bitterness was even scored slightly higher for EPC (6.0 (SEM 0.3)) than for FPC (4.8 (SEM 0.2$)$ ) and, on the contrary, granularity being scored $5 \cdot 0$ (SEM 0.2) and 6.3 (SEM 0.3), respectively (Fig. 1).

Thus, $1.5 \%$-enriched creams were selected as the final products to be tested in the bioavailability study and will be

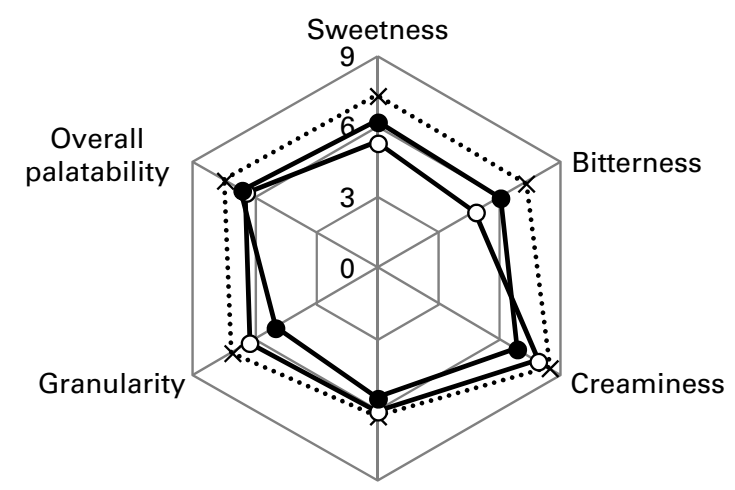

Fatness

Fig. 1. Hedonic profile of control cream (***), and experimental creams enriched with $1.5 \%$ of free (FP, - - ) and encapsulated (EP, - ) cocoa polyphenol extract. Values are mean scores ( $n 30$ ) anchored by 0 (extremely disliking) to 9 (extremely liking). 
here-after indicated as FPC (the one containing 1.5\% free cocoa polyphenol extract) and EPC (the one containing $1.5 \%$ encapsulated cocoa polyphenol extract).

\section{Bioavailability study}

Serum. Fig. 3 shows the mean serum concentration-time curves of total flavanols and phenolic acids found in subjects following consumption of experimental cocoa-nut creams.

None of monitored flavanols (i.e. (epi)catechin, epigallocatechin and procyanidin $\mathrm{B}_{1}$ ) was found in serum at baseline. Only (epi)catechin was found in serum of subjects after consumption of FPC and EPC, while it was absent after CC consumption. In particular, (epi)catechin reached a concentration peak $\left(C_{\max }=4 \cdot 1(\operatorname{sem} 2 \cdot 3) \mathrm{nmol} / \mathrm{l}\right) 1 \mathrm{~h}$ after FPC consumption and it slowly returned to baseline value at $6 \mathrm{~h}$ post-consumption. After EPC consumption, the increase of serum (epi)catechin from baseline was significantly lower $\left(C_{\max }=0.9(\operatorname{sem} 0.6) \mathrm{nmol} / \mathrm{l}\right)$ than after FPC and was found only within the first hour after consumption. Accordingly, $\mathrm{AUC}_{0-6}$ of (epi)catechin after FPC was 13.9-fold higher than that found after $\operatorname{EPC}(7 \cdot 4(\operatorname{SEM} 4 \cdot 4)$ v. 0.5 (SEM $0 \cdot 3)$ nmol/1 $\times$ h, respectively; $P<0.05)$.

Serum concentration of total phenolic acids at baseline was always about $135 \cdot 2$ (sEm 19·1) nmol/1, without the differences among treatments; after consumption of the creams, it was always higher than baseline. At 30 min after FPC consumption, serum phenolic acid concentration was higher than that found after EPC and CC (198.3 (SEM 101·0) v. $37 \cdot 2$ (SEM 17·2) and 24.8 (SEm 5.2) nmol/1, respectively), while the latter cream guaranteed a much higher concentration of phenolic acids (approximately $150 \mathrm{nmol} / \mathrm{l}$ ) at both 6 and $24 \mathrm{~h}$ after consumption compared to the cocoa polyphenol-enriched creams (approximately $25 \mathrm{nmol} / \mathrm{l}$ ).

The phenolic acids retrieved in serum samples and the relative amounts are reported in Table 3 .

No significant difference was recorded in serum total phenolic acid concentrations following CC and FPC consumption, while a significantly lower amount was found after EPC consumption (726.8 (SEM 73.44) v. 1954.26 (SEM 236.33) and $1459 \cdot 37$ (SEM 137.63) nmol, respectively).

Urine. Fig. 4 shows the mean urinary excretion-time curves of total catechins and phenolic acids found in subjects following consumption of experimental cocoa-nut creams.

(Epi)catechins and procyanidins were never found in the urine of subjects at baseline, while they were retrieved after consumption of all the creams. In particular, within $4 \mathrm{~h}$ from CC consumption, their total concentration reached a plateau value that was maintained for up to $8 \mathrm{~h}$, returned to baseline value at $10 \mathrm{~h}$ and was again higher than baseline at $24 \mathrm{~h}$. After FPC consumption, only one concentration peak within the $2 \mathrm{~h}$ from consumption was found, while after EPC, catechin and procyanidin excretion was always negligible. However, only EPC always elicited a lower excretion of total flavanols than CC and FPC, while urinary excretion of total flavanols after FPC was significantly reduced compared to that after CC, only after the consumption of the second cream portion $\left(\mathrm{AUC}_{6-24}\right.$ being $9 \cdot 1$ (SEm 6.3) and $62 \cdot 0$ (SEM $42 \cdot 0) \mathrm{nmol} / \mathrm{l} \times \mathrm{h}$, respectively).

According to serum data, the concentration of phenolic acids that were retrieved from baseline urine samples (approximately 25.3 (SEM 2.0) $\mu \mathrm{mol} / \mathrm{l}$, with no differences between treatments) and after cream consumption was approximately 1000-fold higher than that of total flavanols. Moreover, EPC elicited the lowest excretion, both over the first $6 \mathrm{~h}$ and over the $24 \mathrm{~h}$ after consumption, while a significantly higher excretion of phenolic acids following FPC than CC consumption was recorded only within $6 \mathrm{~h}$ after consumption (see Table 4). Apart from those found in serum samples, urinary phenolic acids also comprised of ferulic acid, dihydroferulic acid, protocatechuic acid, coumaric acid, caffeic acid and dihydrocaffeic acid.

Faeces. Flavanols were never found in faeces collected at baseline, and their amount after consumption of EPC (150.97 (SEM 54.65) nmol) was higher than after consumption of FPC (27.98 (sem 13.97) nmol) and CC (4.27 (sem 4.52) nmol) (Table 5).

Table 3. Amount (nmol) of serum-free native flavanols and phenolic acids over the time intervals $0-6 \mathrm{~h}$ following consumption of the three cocoa creams

(Mean values with their standard errors $(n 12))$

\begin{tabular}{|c|c|c|c|c|c|c|}
\hline & \multicolumn{2}{|c|}{$\mathrm{CC}$} & \multicolumn{2}{|c|}{ FPC } & \multicolumn{2}{|c|}{ EPC } \\
\hline & Mean & SEM & Mean & SEM & Mean & SEM \\
\hline \multicolumn{7}{|l|}{ Flavanols (nmol) } \\
\hline (Epi)catechin & \multicolumn{2}{|c|}{ ND } & $22 \cdot 07^{\star}$ & $2 \cdot 62$ & $1.59^{*} \dagger$ & 0.22 \\
\hline \multicolumn{7}{|l|}{ Phenolic acids (nmol) } \\
\hline Vanillic acid & $32 \cdot 57$ & $2 \cdot 29$ & $7 \cdot 53^{*}$ & 0.86 & $15 \cdot 31^{*} \dagger$ & 1.51 \\
\hline Chlorogenic acid & $5 \cdot 48$ & 0.67 & $13 \cdot 93^{\star}$ & 1.59 & $4 \cdot 19^{*}$ & 0.53 \\
\hline Hippuric acid & 1386 & $196 \cdot 1$ & $994.7^{\star}$ & $90 \cdot 89$ & $318 \cdot 7^{*} \dagger$ & $42 \cdot 32$ \\
\hline Hydroxybenzoic acid & $480 \cdot 2$ & $32 \cdot 64$ & $318 \cdot 8^{*}$ & $27 \cdot 64$ & $332 \cdot 9^{*} \dagger$ & $24 \cdot 13$ \\
\hline DHPV & $16 \cdot 87$ & 0.82 & $115 \cdot 2^{*}$ & $15 \cdot 36$ & $29 \cdot 18^{*} \dagger$ & 2.47 \\
\hline HPA & $16 \cdot 78$ & 1.82 & $3.04^{*}$ & 0.43 & $5 \cdot 63^{*}$ & 0.67 \\
\hline HPP & $15 \cdot 82$ & $2 \cdot 01$ & $6 \cdot 12^{\star}$ & 0.87 & $20 \cdot 92^{*}$ & 1.81 \\
\hline Total & 1954 & $236 \cdot 3$ & 1459 & 137.6 & $726 \cdot 8^{*} \dagger$ & 73.44 \\
\hline
\end{tabular}

CC, control cream; FPC, cream enriched with $1.5 \%(\mathrm{w} / \mathrm{w})$ of the free cocoa polyphenol extract; EPC, cream enriched with $1.5 \%$ $(\mathrm{w} / \mathrm{w})$ of the encapsulated cocoa polyphenol extract; ND, not determined; DHPV, 5-( $3^{\prime}, 4^{\prime}$-dihydroxyphenyl)- $\gamma$-valerolactone; HPA, 4-hydroxyphenylacetic acid; HPP, 3-(4-hydroxyphenyl) propionic acid.

* Mean values were significantly different from that of $C C(P<0.05$; Bonferroni test).

† Mean values were significantly different from that of FPC $(P<0.05$; Bonferroni test). 
Table 4. Amount (nmol) of parental flavanols and phenolic acids excreted in urine collected over the time intervals $0-6$ and $6-24 \mathrm{~h}$ following consumption of the three nut-cocoa creams

(Mean values with their standard errors $(n 12))$

\begin{tabular}{|c|c|c|c|c|c|c|c|c|c|c|c|c|}
\hline & \multicolumn{4}{|c|}{$\mathrm{CC}$} & \multicolumn{4}{|c|}{ FPC } & \multicolumn{4}{|c|}{ EPC } \\
\hline & \multicolumn{2}{|c|}{$0-6 \mathrm{~h}$} & \multicolumn{2}{|c|}{$6-24 \mathrm{~h}$} & \multicolumn{2}{|c|}{$0-6 \mathrm{~h}$} & \multicolumn{2}{|c|}{$6-24 \mathrm{~h}$} & \multicolumn{2}{|c|}{$0-6 \mathrm{~h}$} & \multicolumn{2}{|c|}{$6-24 \mathrm{~h}$} \\
\hline & Mean & $\overline{\text { SEM }}$ & Mean & SEM & Mean & $\overline{\text { SEM }}$ & Mean & SEM & Mean & SEM & Mean & SEM \\
\hline \multicolumn{13}{|l|}{ Flavanols (nmol) } \\
\hline (Epi)catechin & $5 \cdot 26$ & 3.72 & 11.75 & $7 \cdot 16$ & 4.82 & 3.41 & $2 \cdot 16^{\star}$ & 1.53 & & & & \\
\hline EGC & 0.02 & 0.01 & 0.50 & 0.35 & & & & & 0.19 & 0.14 & $2.00 \dagger$ & 1.42 \\
\hline Procyanidin & 0.39 & 0.24 & 1.17 & 0.82 & 0.85 & 0.47 & 1.83 & 1.29 & & & 2.73 & $1 \cdot 80$ \\
\hline Total & 5.68 & 3.97 & 13.42 & 8.33 & 5.67 & 3.88 & 4.00 & $2 \cdot 82$ & 0.19 & 0.14 & 4.73 & $3 \cdot 22$ \\
\hline \multicolumn{13}{|l|}{ Phenolic acids (nmol) } \\
\hline Protocatechuic acid & $42 \cdot 0$ & $15 \cdot 2$ & $420 \cdot 4$ & $139 \cdot 3$ & 22.9 & $9 \cdot 0$ & $548 \cdot 2$ & $180 \cdot 0$ & $9 \cdot 6^{*}$ & $4 \cdot 2$ & 693.7 & $252 \cdot 2$ \\
\hline Ferulic acid & $15 \cdot 2$ & $5 \cdot 3$ & $1340 \cdot 4$ & 533.6 & $67 \cdot 9^{*}$ & 38.2 & 91.6 & $51 \cdot 2$ & $19 \cdot 1$ & 9.2 & $1024 \cdot 1$ & 315.9 \\
\hline Vanillic acid & $6 \cdot 3$ & 2.9 & 338.4 & $110 \cdot 4$ & $34.4^{*}$ & $11 \cdot 2$ & 452.2 & 192.5 & $16 \cdot 3$ & $10 \cdot 2$ & 195.9 & 84.1 \\
\hline Caffeic acid & 1.4 & 0.6 & $99 \cdot 0$ & $29 \cdot 7$ & 2.5 & 0.9 & 74.3 & $18 \cdot 7$ & 0.5 & 0.3 & 21.3 & $7 \cdot 7$ \\
\hline Coumaric acid & 1.2 & 0.6 & 23.9 & $13 \cdot 0$ & $3 \cdot 1$ & 1.4 & 34.4 & $12 \cdot 4$ & 1.4 & 0.4 & 38.5 & $12 \cdot 4$ \\
\hline Chlorogenic acid & 0.1 & 0.0 & 1.9 & 0.5 & 0.2 & 0.0 & 1.4 & 0.6 & 0.4 & 0.2 & $2 \cdot 9$ & 0.9 \\
\hline Hippuric acid & 2279 & 1411 & 98571 & 45317 & $8562^{*}$ & 3854 & 44321 & 20004 & $341 \cdot 0^{*} \dagger$ & $241 \cdot 1$ & 4128 & 2919 \\
\hline Homovanillic acid & $515 \cdot 8$ & $160 \cdot 7$ & 48861 & 17674 & $2023^{*}$ & 802.9 & 48489 & 16071 & 223.4 & $156 \cdot 4$ & 32110 & 7995 \\
\hline DHPA & $122 \cdot 1$ & $72 \cdot 7$ & 6205 & 2881 & 199.5 & 73.6 & 10911 & 3986 & $117 \cdot 2$ & 48.6 & 3467 & 1139 \\
\hline Di-HCA & $40 \cdot 6$ & 14.5 & 2106 & $896 \cdot 2$ & 94.6 & 31.3 & 2417 & $749 \cdot 1$ & $34.4 \dagger$ & 11.5 & 1915 & $566 \cdot 3$ \\
\hline Hydroxybenzoic acid & $22 \cdot 2$ & $12 \cdot 3$ & $470 \cdot 7$ & $156 \cdot 2$ & $31 \cdot 1$ & $19 \cdot 8$ & $269 \cdot 0$ & $189 \cdot 2$ & $42 \cdot 4$ & 19.5 & 1202 & $536 \cdot 6$ \\
\hline Di-HFA & $10 \cdot 1$ & 4.5 & $449 \cdot 7$ & $318 \cdot 0$ & $302 \cdot 1^{\star}$ & $177 \cdot 0$ & $313 \cdot 7$ & $163 \cdot 3$ & $60 \cdot 7^{*} \dagger$ & $34 \cdot 3$ & 104.9 & $51 \cdot 2$ \\
\hline HPP & 3.4 & $2 \cdot 1$ & $30 \cdot 2$ & $10 \cdot 4$ & $1 \cdot 1$ & 0.6 & $3 \cdot 3^{\star}$ & 1.5 & 0.1 & 0.0 & $2 \cdot 2^{*}$ & 1.6 \\
\hline HPA & $2 \cdot 6$ & 1.2 & $87 \cdot 6$ & 42.5 & $64 \cdot 2^{*}$ & $37 \cdot 7$ & $78 \cdot 0$ & $40 \cdot 0$ & $24 \cdot 3^{*}$ & 10.5 & 11.4 & $7 \cdot 2$ \\
\hline DHPV & 0.3 & 0.1 & $9 \cdot 2$ & 3.0 & 0.4 & 0.2 & 3.1 & 1.4 & 0.9 & 0.3 & $3 \cdot 2$ & 1.5 \\
\hline Total & 3062 & 1703 & 159015 & 68124 & $11409^{*}$ & 5058 & 108007 & 41661 & $891 \cdot 7^{*} \dagger$ & $546 \cdot 7$ & 44921 & 13890 \\
\hline
\end{tabular}

CC, control cream; FPC, cream enriched with $1.5 \%(\mathrm{w} / \mathrm{w})$ of the free cocoa polyphenol extract; EPC, cream enriched with $1.5 \%$ (w/w) of the encapsulated cocoa polyphenol extract; EGC, epigallocatechin; DHPA, 3,4-dihydroxyphenylacetic acid; Di-HCA, dihydrocaffeic acid; Di-HFA, dihydroferulic acid; HPP, 3-(4-hydroxyphenyl)propionic acid; HPA, 4-hydroxyphenylacetic acid; DHPV, dihydroxyphenyl- $\gamma$-valerolactone.

${ }^{*}$ Mean values were significantly different from that of $\mathrm{CC}(P<0.05$; Bonferroni test $)$.

$\dagger$ Mean values were significantly different from that of FPC $(P<0.05$; Bonferroni test $)$.

Table 5. Amount (nmol) of parental flavanols and phenolic acids excreted in faeces collected the day after consumption of the three nut-cocoa creams

(Mean values with their standard errors $(n 12)$ )

\begin{tabular}{|c|c|c|c|c|c|c|}
\hline & \multicolumn{2}{|c|}{$\mathrm{CC}$} & \multicolumn{2}{|c|}{ FPC } & \multicolumn{2}{|c|}{ EPC } \\
\hline & Mean & SEM & Mean & SEM & Mean & SEM \\
\hline \multicolumn{7}{|l|}{ Flavanols (nmol) } \\
\hline (Epi)catechin & \multicolumn{2}{|c|}{ ND } & $10 \cdot 25$ & $5 \cdot 13$ & 31.54 & 12.44 \\
\hline EGC & $4 \cdot 27$ & 4.52 & \multicolumn{2}{|c|}{ ND } & 0.52 & 0.30 \\
\hline Procyanidin & \multicolumn{2}{|c|}{ ND } & $17 \cdot 73^{\star}$ & 8.84 & $118 \cdot 9^{*} \dagger$ & 41.91 \\
\hline Total & 4.27 & 4.52 & 27.98 & 13.97 & $151 \cdot 0^{*} \dagger$ & 54.65 \\
\hline \multicolumn{7}{|l|}{ Phenolic acids (nmol) } \\
\hline Ferulic acid & $42 \cdot 58$ & 6.33 & \multicolumn{2}{|c|}{ ND } & \multicolumn{2}{|c|}{ ND } \\
\hline PCA & $25 \cdot 13$ & $6 \cdot 31$ & $4.69^{\star}$ & 0.00 & $9.65^{*}$ & 0.11 \\
\hline Vanillic acid & 8.46 & 1.91 & \multicolumn{2}{|c|}{ ND } & \multicolumn{2}{|c|}{ ND } \\
\hline Coumaric acid & 8.01 & 1.25 & \multicolumn{2}{|c|}{ ND } & 4.56 & 2.34 \\
\hline Caffeic acid & 1.67 & 0.00 & $2 \cdot 67^{*}$ & 0.00 & \multicolumn{2}{|c|}{ ND } \\
\hline Chlorogenic acid & 0.86 & 0.43 & $0.05^{*}$ & 0.01 & 0.04 & 0.00 \\
\hline Homovanillic acid & 322.2 & 0.00 & \multicolumn{2}{|c|}{ ND } & \multicolumn{2}{|c|}{ ND } \\
\hline Di-HCA & 141.3 & 38.61 & \multicolumn{2}{|c|}{ ND } & \multicolumn{2}{|c|}{ ND } \\
\hline Di-HFA & 37.75 & 27.94 & \multicolumn{2}{|c|}{ ND } & \multicolumn{2}{|c|}{ ND } \\
\hline HPP & 53.44 & $16 \cdot 28$ & \multicolumn{2}{|c|}{ ND } & \multicolumn{2}{|c|}{ ND } \\
\hline DHPV & \multicolumn{2}{|c|}{ ND } & 0.70 & 0.12 & 0.41 & 0.23 \\
\hline Total & 641.4 & 99.07 & $8 \cdot 11^{*}$ & 0.13 & $14 \cdot 66^{*}$ & 2.68 \\
\hline
\end{tabular}

CC, control cream; FPC, cream enriched with $1.5 \%(\mathrm{w} / \mathrm{w})$ of the free cocoa polyphenol extract; EPC, cream enriched with $1.5 \%(\mathrm{w} / \mathrm{w})$ of the encapsulated cocoa polyphenol extract; ND, not determined; EGC, epigallocatechin; PCA, protocatechuic acid; Di-HCA, dihydrocaffeic acid; Di-HFA, dihydroferulic acid; HPP, 3-(4-hydroxyphenyl)propionic acid; DHPV, dihydroxyphenyl- $\gamma$-valerolactone.

${ }^{*}$ Mean values were significantly different from that of $C C(P<0.05$; Bonferroni test).

† Mean values were significantly different from that of FPC $(P<0.05$; Bonferroni test). 
On the contrary, the amount of phenolic acids retrieved in faeces at $24 \mathrm{~h}$ following CC consumption (641.43 (SEM 99.07) nmol) was the only one to be higher than that found at baseline (1767.64 (SEM 594.27) nmol, without differences among treatments) and after FPC (8.11 (SEM 0.13) nmol) and EPC (14.66 (SEM 2.68) nmol) consumption.

The bioavailability data have been summarised in Table 6 to gain the complete picture of the distribution of the ingested bioactive compounds.

\section{Discussion}

Enrichment of foods with catechin and epicatechin can be difficult due to their bitter taste and astringency in the mouth. Encapsulating flavanols with a coating material inaccessible by salivary enzymes, such as HACS, can overcome this problem. The cocoa-nut cream enriched with microencapsulated cocoa flavanols (EPC) used in the present study showed a slightly higher hedonic for bitterness than the cream added with the ingredient in the free form (FCP; see Fig. 1).

Testing the bioavailability of the encapsulated bioactive compounds from enriched foods is fundamental to foresee their in vivo bioactivity. To our knowledge, the present study is the first study evaluating cocoa flavanol and phenolic acid bioavailability from cocoa-nut creams in human subjects. The study was designed to follow the fate of parental and free cocoa polyphenols after the consumption of one portion of three cocoa-nut creams $(33 \mathrm{~g})$ differing in amount (CC $v$. FPC) and form (FPC $v$. EPC) of contained cocoa polyphenols and of a total of $99 \mathrm{~g}$ cream (three portions) distributed throughout the day (one portion at each daily meal, i.e. at breakfast, lunch and dinner; see Fig. 2). Thus, the comparison between CC and FPC allowed us to evaluate the effect of dose on bioavailability of free parental flavanols and of phenolic acids contained in the creams, while comparison between FPC and EPC allowed us to investigate the effect of microencapsulation of the bioactive compounds.

Data indicated that flavanol absorption at $6 \mathrm{~h}$ after the consumption of cocoa-nut creams was dose-dependent, as previously reported after cocoa and chocolate consumption $^{(8,15-20)}$. In fact, as summarised in Table 6, after consumption of one CC portion, flavanols were not detected in the bloodstream, while consumption of FPC, containing an almost doubled amount of free monomers, determined (epi)catechin presence in the serum. The time-course values of (epi)catechin concentration in serum and urine following FPC consumption (Figs. 3(a) and 4(a)) demonstrated a rapid absorption $\left(t_{\max }=1 \mathrm{~h}\right.$ ) and excretion (within $2 \mathrm{~h}$ ) upon consumption. The rapid absorption and serum clearance of parental (epi)catechin after cocoa-nut cream $\left(t_{\max }\right.$ at $1 \mathrm{~h}$ and absence of compounds at $6 \mathrm{~h}$ ) was consistent with literature data on the bioavailability of epicatechin from cocoa and chocolate, thus confirming the occurrence of gastric absorption and a rapid plasma clearance (within $6 \mathrm{~h}$ from consumption) of compounds ${ }^{(30-32)}$. This feature was corroborated by data obtained after consumption of EPC, which elicited a 10-fold lower amount of serum (epi)catechin than FPC. In fact, as about $50 \%(195 \cdot 3 \mu \mathrm{mol}$ of a total $385.3 \mu \mathrm{mol} / 100 \mathrm{~g}$ of cream)

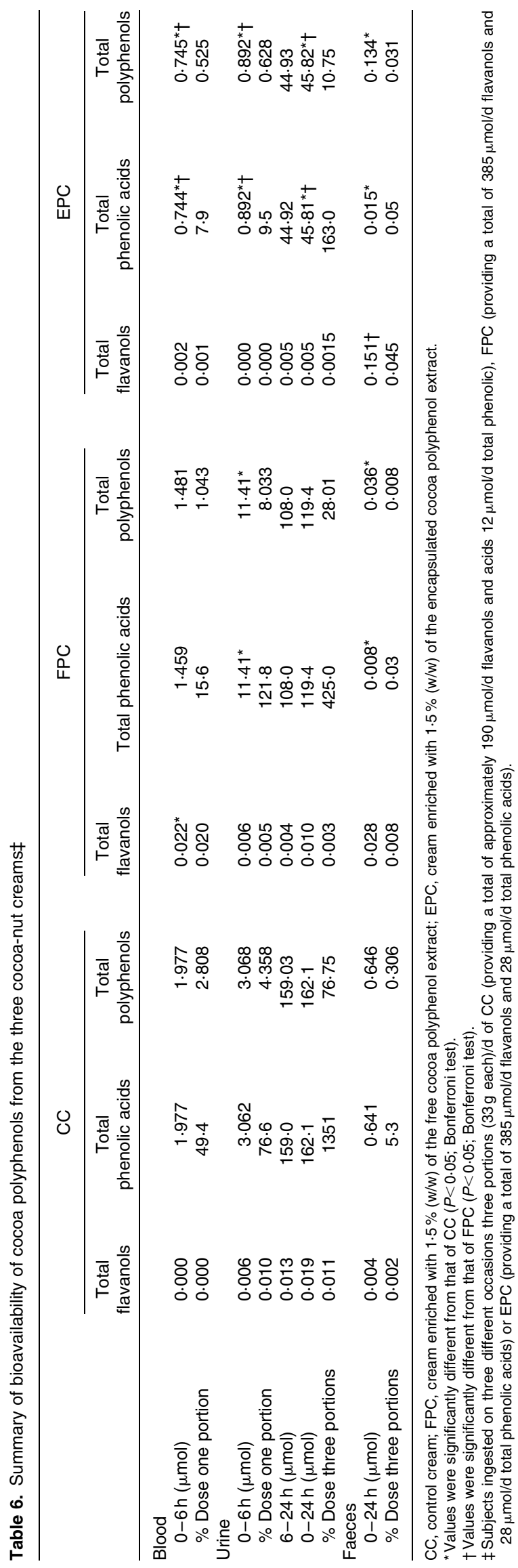




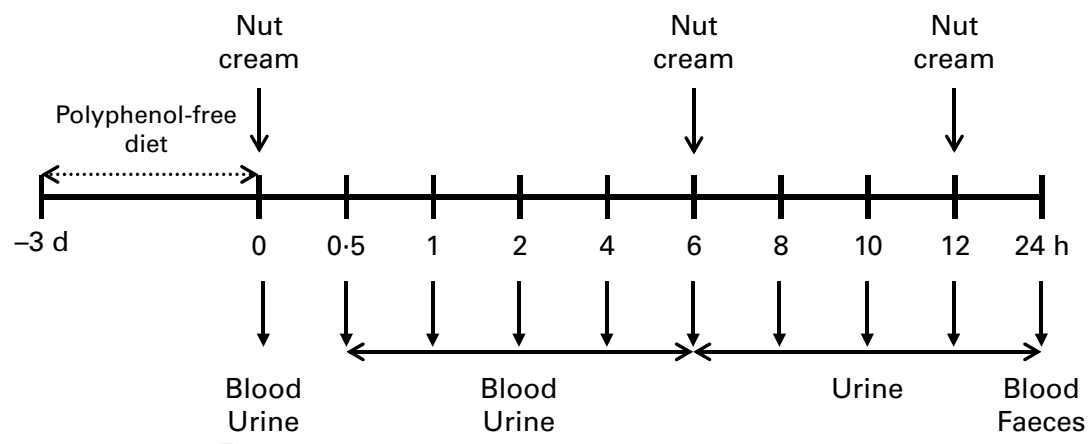

Fig. 2. Study design. Each subject followed the time schedule for each type of cocoa-nut cream by a cross-over randomised design. After a 1-week wash-out period during which subjects returned to their habitual diet, they switched to the 3-d polyphenol-free diet and were randomised for another treatment. A total of three portions ( $33 \mathrm{~g}$ each) of the cocoa-nut cream were consumed upon each treatment.

of cocoa flavanols in EPC were encapsulated by a coating material resistant to gastric digestion (HACS), their gastric absorption was reduced compared to $\mathrm{FPC}^{(33)}$. Moreover, we hypothesised that the higher amount of dietary fibre in EPC $(+7 \cdot 2 \%$, due to the HACS coating) might slow gastric emptying rate ${ }^{(34)}$, thus blunting free epicatechin absorption compared to CC. A slower arrival of total flavanols (the half deriving from cocoa as in CC plus the half encapsulated) in the intestine after consumption of EPC might have also caused an increased formation of conjugated metabolites at the level of intestinal mucosa or liver, as a consequence of a lower amount of substrate per unitary time than after ingestion of CC and FPC. This hypothesis justified the missed detection in urine of the monitored cocoa native and free flavanols and the much lower procyanidin concentrations found after EPC consumption compared to CC and FPC consumption

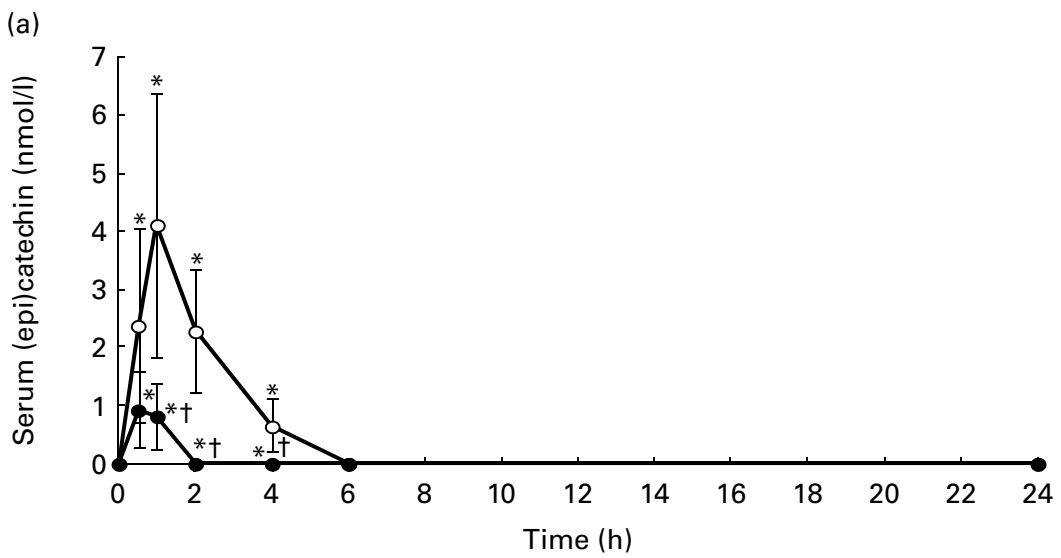

(b)

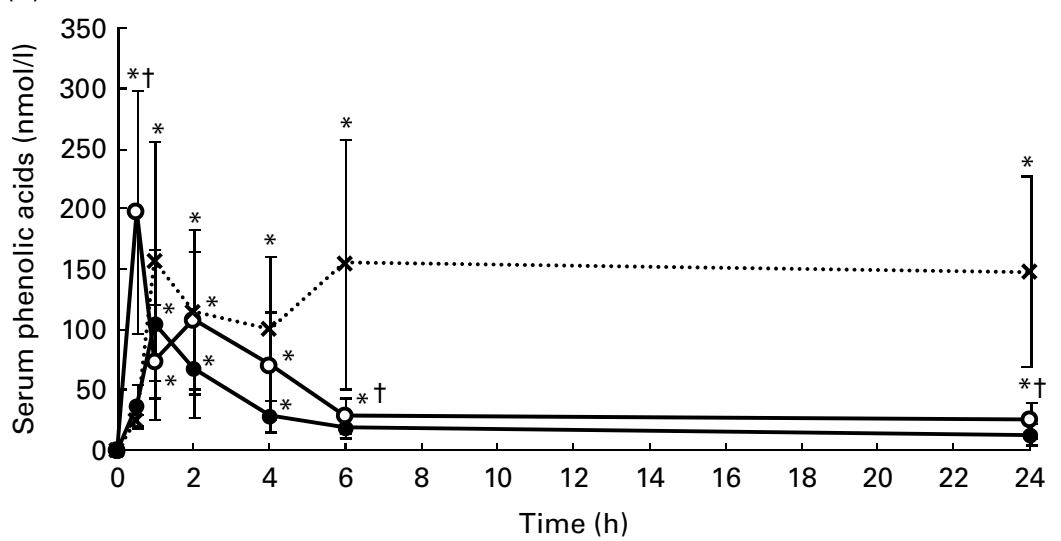

Fig. 3. Serum concentration-time curves of (a) (epi)catechin and (b) total phenolic acids over $24 \mathrm{~h}$ following consumption of the three types of cream (CC, control cream; FPC, free cocoa polyphenol cream; EPC, encapsulated cocoa polyphenol cream). (a) -O-, FPC; - - EPC. (b) -O-, FPC; - - , EPC; $\cdots \cdots \cdots$, CC. Values are means, with their standard errors represented by vertical bars $(n 12)$. ${ }^{*}$ Mean values were significantly different from that of time $0(P<0.05$; Bonferroni test). † Mean values were significantly different from that of $\mathrm{CC}(P<0.05$; Bonferroni test). 
(a)
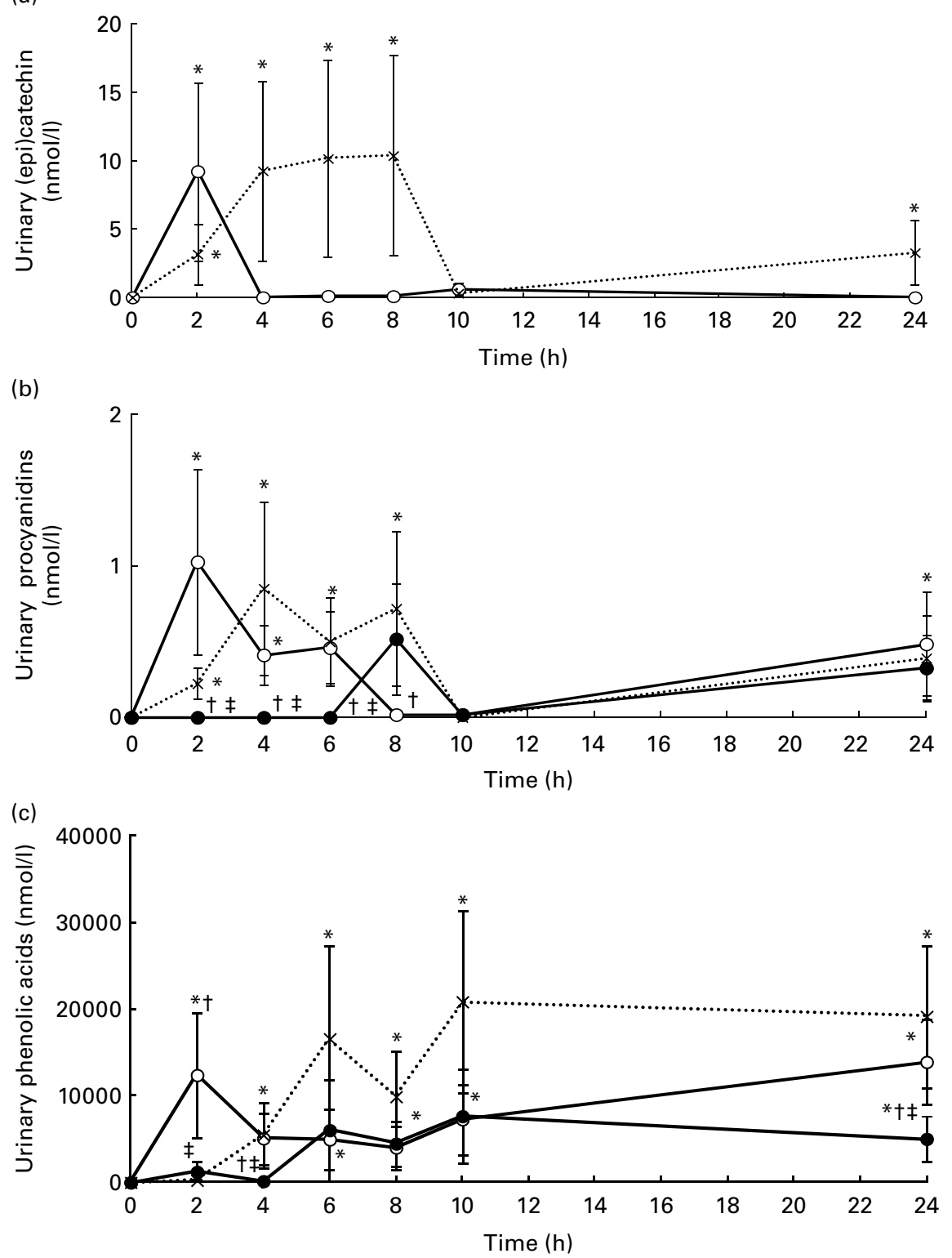

Fig. 4. Urinary excretions of (a) (epi)catechin, (b) procyanidins and (c) total phenolic acids over $24 \mathrm{~h}$ following consumption of the three types of cream (CC, control cream; FPC, free cocoa polyphenol cream; EPC, encapsulated cocoa polyphenol cream). Values are means, with their standard errors represented by vertical

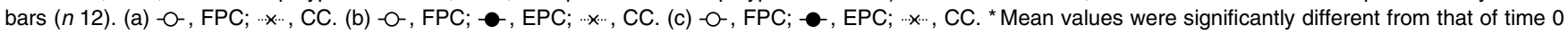
$(P<0.05$; Bonferroni test). $†$ Mean values were significantly different from that of $C C(P<0.05$; Bonferroni test).

(see Fig. 4(a) and (b)). Encapsulation of polyphenols might influence gastric emptying and in turn modify metabolism of the part of flavanols present in EPC that were not encapsulated.

Looking at the time-course values of phenolic acids in serum and in urine, a double concentration peak was found: the first at $30 \mathrm{~min}-1 \mathrm{~h}$ and the second at $4-6 \mathrm{~h}$ after consumption. They could account for the absorption of cocoanut cream parental phenolic acids from the stomach and for the absorption of compounds delivered in the intestine by the ring scission of procyanidins or flavones and/or by hydrolysis from cocoa fibres, as previously demonstrated or suggested in vitro ${ }^{(35,12)}$. In fact, Ortega et al. ${ }^{(35)}$ demonstrated an increased amount of phenolic acids (mainly hydroxybenzoic, syringic and chlorogenic acids) in the bioaccessible fraction deriving from both gastric and duodenal digestion of cocoa liquor and cocoa powder, compared to the amount present in the food matrices. Accordingly, in a previous work, we showed that pancreatin digestion of water-insoluble cocoa dietary fibre led to a soluble fraction (correspondent to the bioaccessible moiety), exerting the same antioxidant capacity of pepsin fraction despite a reduced concentration of catechins, and thus suggesting that other antioxidant compounds might form in the medium at intestinal-simulated conditions ${ }^{(12)}$.

Anyway, the total flavanols found in the parental form in blood and urine within $6 \mathrm{~h}$ from consumption, compared to 
the dose ingested, were $0 \cdot 010 \%$ after CC, $0.025 \%$ after FPC and $0.002 \%$ after EPC. Percentages below $0 \cdot 1 \%$ of the ingested dose for native free flavanols were expected, as it is known that flavanols are mainly metabolised by the liver and intestine. In fact, authors reporting plasma concentration, of flavanols from $257 \mathrm{nmol} / 1$ up to $6-12 \mu \mathrm{mol} / 1,1-2 \mathrm{~h}$ after consumption of 40-100 g of commercial cocoa or high-flavanol cocoa or chocolate, always analysed samples after treatment with glucuronidase, thus summing both free and metabolised compounds ${ }^{(9,18,19,30,32,36)}$. As we did not perform glucuronidase treatment on samples, we measured the compounds present in biological samples in the free form. Only in the study by Schroeter et al. ${ }^{(22)}$, both parent compounds and their metabolite concentrations in plasma at $2 \mathrm{~h}$ after high-flavanol cocoa consumption were shown to be approximately 300 and $1400 \mathrm{~nm}$, respectively. Thus, in that case, after ingestion of $604 \mu \mathrm{mol}$ of flavanol monomers in cocoa, a concentration ratio between epicatechins and glucuronides of 1:4 could be calculated. Indeed, in the present study, after consumption of cocoa-nut creams containing 190-385 $\mu \mathrm{mol}$ of total flavanols and $12-28 \mu \mathrm{mol}$ of phenolic acids per $100 \mathrm{~g}$ of cream, serum maximum concentration of (epi)catechin ranged between 0 and $4 \mathrm{~nm}$, while concentration of total phenolic acids was between 100 and $200 \mathrm{~nm}$ within $2 \mathrm{~h}$ after consumption (see Fig. 3(b)). Thus, within $2 \mathrm{~h}$ after consumption of cocoa-nut creams, the concentration ratio between (epi)catechin and phenolic acids in serum was 1:50, much higher than that achievable for glucuronidated products.

Phenolic acids in serum, over a time-window shortly following cocoa or chocolate consumption, have never been evaluated in previous studies. Rios et al. ${ }^{(13)}$ quantified phenolic acids in urine collected over $0-48 \mathrm{~h}$ after cocoa consumption. They reported that among the eleven aromatic acids retrieved (3,4-dihydroxyphenylpropionic acid, $m$-hydroxyphenylpropionic, ferulic acid, 3,4-dihydroxyphenylacetic acid, $m$-hydroxyphenylacetic acid, phenylacetic acid, vanillic acid, $m$-hydroxybenzoic acid, $p$-hydroxybenzoic acid, $p$-hydroxyhippuric acid and hippuric acid) only vanillic acid showed a peak excretion shortly after chocolate consumption $(0-3 \mathrm{~h})$, probably deriving from oxidation of vanillin present in the chocolate, while the other phenolic acids increased starting from $6 \mathrm{~h}$ after consumption. However, Urpi-Sarda et al. ${ }^{(37)}$ successively showed that, although phenolic acids were most abundant in urine collected after $6 \mathrm{~h}$ from consumption, concentrations higher than baseline values were retrieved in the 0-6h time interval for 3,4-dihydroxyphenylacetic acid, five hydroxybenzoic acids and two hydroxycinnamic acids; moreover, they found that when the cocoa beverage was prepared with milk, compared to water, vanillic acid was more abundant and majorly excreted over the first $6 \mathrm{~h}$ after consumption ${ }^{(37)}$.

The different matrices tested (chocolate by Rios et al. ${ }^{(13)}$; Urpi-Sarda et $a{ }^{(37)}$ cocoa beverage prepared with water or milk and cocoa-nut creams in the present study) might account for the different results obtained by the studies. However, looking at $0-6 \mathrm{~h}$ urinary excretion of phenolic acids following CC and FPC consumption, the present data indicated a dose-dependence from ingested flavanol monomers and phenolic acids excreted. This feature was reinforced by the data recorded after EPC consumption: when cocoa polyphenols were partly encapsulated, phenolic acids were markedly reduced over $0-6 \mathrm{~h}$ time intervals, while an increased rate of excretion after $6 \mathrm{~h}$ was recorded. These results suggested that flavanols, other than cocoa dietary fibres, might contribute to the phenolic acid formation in the short term and confirmed the major role of gut microflora on phenolic acid formation in the long term ${ }^{(8,10-14)}$. In fact, the higher amount of flavanols in the faeces collected after consumption of EPC, than in those after FPC, together with an equivalent amount of phenolic acids indicated that the encapsulation allowed the delivery of bioactive compounds in the lower gut and the successive metabolism by local microflora (see Figs. 3(b) and 4(b), $24 \mathrm{~h}$ time point).

Despite the fact that FPC caused the highest phenolic acid excretion over the first $6 \mathrm{~h}$ after consumption, the amount of phenolic acids excreted in 24-h urine following its consumption did not differ by that recorded after CC, both being consistent with that observed by Rios et al. ${ }^{(13)}$ after consumption of $80 \mathrm{~g}$ chocolate. It may be possible that a different concentration ratio of monomers (not absorbed and/or degraded in the upper gastro-intestinal tract) and oligomers plus polymers (naturally reaching the gut) in the gut after consumption of the three creams might differently influence microflora metabolism and absorption of metabolites over the $24 \mathrm{~h}$.

All in all, the present data demonstrated that parental cocoa flavanols are absorbed by cocoa-nut creams in a dose-dependent manner and phenolic acids are the major metabolites in the short term, being at a concentration ratio of 50:1 $v$. (epi)catechin. Encapsulation of cocoa polyphenols with HACS caused a reduced 24-h bioavailability of these compounds. On the other hand, encapsulation effectively masked bitter taste and allowed delivering of flavanol monomers into the gut. From the nutritional point of view, encapsulated cocoa polyphenols may be considered as a functional prebiotic ingredient, as evidenced in a recent human study ${ }^{(38)}$. Further studies should be performed to test this hypothesis and to evaluate the in vivo efficacy of this ingredient towards specific pathologies and functions.

\section{Acknowledgements}

The present research was conducted in the frame of NANOFOODS project funded by the European Commission (Project no: 222006). There are no conflicts of interest. The authors' contributions are as follows: P. V. and V. F. designed the research; P. V., R. B. L. and V. F. wrote the paper; P. V., R. F., R. B. L. and S. S. conducted the sensory and bioavailability study; José Ramón Morelló, Jordi Reguant Miranda and E. S. developed the creams; P. V., R. F. and R. B. L. analysed the data; P. V. and V. F. had the primary responsibility for the final content. All authors read and approved the final manuscript.

\section{References}

1. Keen CL, Holt RR, Oteiza PI, et al. (2005) Cocoa antioxidants and cardiovascular health. Am J Clin Nutr 81, 298-303. 
2. Buijsse B, Feskens EJ, Kok FJ, et al. (2006) Cocoa intake, blood pressure, and cardiovascular mortality: the Zutphen Elderly Study. Arch Intern Med 166, 411-417.

3. Santos-Buelga C \& Scalbert A (2000) Proanthocyanidins and tannin-like compounds: nature, occurrence, dietary intake and effects on nutrition and health. I Sci Food Agric 80, 1094-1117.

4. Cooper KA, Campos-Gimenez E, Jimenez Alvarez D, et al. (2008) Predictive relationship between polyphenol and nonfat cocoa solids content of chocolate. J Agric Food Chem 56, 260-265.

5. Wollgast J \& Anklam E (2000) Review on polyphenols in Theobroma cacao: changes in composition during the manufacture of chocolate and methodology for identification and quantification. Food Res Int 33, 423-447.

6. Gu L, House SE, Wu X, et al. (2006) Procyanidin and catechin contents and antioxidant capacity of cocoa and chocolate products. J Agric Food Chem 54, 4057-4061.

7. INRA polyphenols database. http://www.phenol-explorer.eu/

8. Urpi-Sarda M, Monagas M, Khan N, et al. (2009) Epicatechin, procyanidins, and phenolic microbial metabolites after cocoa intake in humans and rats. Anal Bioanal Chem 394, $1545-1556$

9. Holt RR, Lazarus SA, Sullards MC, et al. (2002) Procyanidin

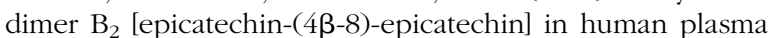
after the consumption of a flavanol-rich cocoa. Am J Clin Nutr 76, 798-804.

10. Appeldoorn MM, Vincken JP, Aura AM, et al. (2009) Procyanidin dimers are metabolized by human microbiota with 2-(3,4-dihydroxyphenyl)acetic acid and 5-(3,4-dihydroxyphenyl)- $\boldsymbol{\gamma}$-valerolactone as the major metabolites. J Agric Food Chem 57, 1084-1092.

11. Stoupi S, Williamson G, Drynan JW, et al. (2010) A comparison of the in vitro biotransformation of $(-)$-epicatechin and procyanidin $\mathrm{B}_{2}$ by human faecal microbiota. Mol Nutr Food Res 54, 747-759.

12. Fogliano V, Corollaro ML, Vitaglione $\mathrm{P}$, et al. (2011) In vitro bioaccessibility and gut biotransformation of polyphenols present in the water-insoluble cocoa fraction. Mol Nutr Food Res 55, Suppl. 1, S44-S55.

13. Rios LY, Gonthier MP, Remesy C, et al. (2003) Chocolate intake increases urinary excretion of polyphenol-derived phenolic acids in healthy human subjects. Am J Clin Nutr 77, 912-918

14. Gonthier MP, Donovan JL, Texier O, et al. (2003) Metabolism of dietary procyanidins in rats. Free Radical Biol Med 35, 837-844.

15. Serafini M, Bugianesi R, Maiani G, et al. (2003) Plasma antioxidants from chocolate. Nature 424, 1013.

16. Neilson AP \& Ferruzzi MG (2011) Influence of formulation and processing on absorption and metabolism of flavan-3ols from tea and cocoa. Annu Rev Food Sci Technol 2, 125-151.

17. Schroeter H, Holt RR, Orozco TJ, et al. (2003) Nutrition: milk and absorption of dietary flavanols. Nature 426, 787-788.

18. Keogh JB, McInerney J \& Clifton PM (2007) The effect of milk protein on the bioavailability of cocoa polyphenols. J Food Sci 72, S230-S233.

19. Roura E, Andres-Lacueva C, Estruch R, et al. (2007) Milk does not affect the bioavailability of cocoa powder flavonoid in healthy human. Ann Nutr Metab 51, 493-498.

20. Roura E, Andres-Lacueva C, Estruch R, et al. (2008) The effects of milk as a food matrix for polyphenols on the excretion profile of cocoa (-)-epicatechin metabolites in healthy human subjects. Br J Nutr 100, 846-851.

21. Mullen W, Borges G, Donovan JL, et al. (2009) Milk decreases urinary excretion but not plasma pharmacokinetics of cocoa flavan-3-ol metabolites in humans. Am J Clin Nutr 89, 1784-1791.

22. Schroeter H, Heiss C, Balzer J, et al. (2006) (-)-Epicatechin mediates beneficial effects of flavanol-rich cocoa on vascular function in humans. Proc Natl Acad Sci U $S$ A 103, 1024-1029.

23. Monagas M, Urpi-Sarda M, Sánchez-Patán F, et al. (2010) Insights into the metabolism and microbial biotransformation of dietary flavan-3-ols and the bioactivity of their metabolites. Food Funct 1, 233-253.

24. Fogliano V \& Vitaglione P (2005) Functional foods: planning and development. Mol Nutr Food Res 49, 256-262.

25. Ortega N, Romero MP, Macià A, et al. (2008) Obtention and characterization of phenolic extracts from different cocoa sources. J Agric Food Chem 56, 9621-9627.

26. Zhongxiang F \& Bhesh B (2010) Encapsulation of polyphenols - a review. Trends Food Sci Technol 21, 510-523.

27. Lucas-Abellán C, Fortea I, Gabaldón JA, et al. (2008) Encapsulation of quercetin and myricetin in cyclodextrins at acidic pH. J Agric Food Chem 56, 255-259.

28. Dube ANg K, Nicolazzo JA \& Larson I (2010) Effective use of reducing agents and nanoparticle encapsulation in stabilizing catechins in alkaline solution. Food Chem 122, 662-667

29. Urpi-Sarda M, Monagas M, Khan N, et al. (2009) Targeted metabolic profiling of phenolics in urine and plasma after regular consumption of cocoa by liquid chromatography-tandem mass spectrometry. J Chromatogr A $\mathbf{1 2 1 6}$ 7258-7267.

30. Richelle M, Tavazzi I, Enslen M, et al. (1999) Plasma kinetics in man of epicatechin from black chocolate. Eur J Clin Nutr 53, 22-26.

31. Rein D, Paglieroni TG, Wun T, et al. (2000) Cocoa inhibits platelet activation and function. Am J Clin Nutr 72, 30-35.

32. Wang JF, Schramm DD, Holt RR, et al. (2000) A doseresponse effect from chocolate consumption on plasma epicatechin and oxidative damage. J Nutr 130, 2115-2119.

33. Anschütz M, Garbacz G, Kosch O, et al. (2009) Characterization of the behavior of alginate-based microcapsules in vitro and in vivo. Int J Clin Pharmacol Ther 47, 556-563.

34. Ray TK, Mansell KM, Knight LC, et al. (1983) Long-term effects of dietary fibre on glucose tolerance and gastric emptying in noninsulin-dependent diabetic patients. Am J Clin Nutr 37, 376-381.

35. Ortega N, Reguant J, Romero MP, et al. (2009) Effect of fat content on the digestibility and bioaccessibility of cocoa polyphenol by an in vitro digestion model. J Agric Food Chem 57, 5743-5749.

36. Baba S, Osakabe N, Yasuda A, et al. (2000) Bioavailability of (-)-epicatechin upon intake of chocolate and cocoa in human volunteers. Free Radic Res 33, 635-641.

37. Urpi-Sarda M, Llorach R, Khan N, et al. (2010) Effect of milk on the urinary excretion of microbial phenolic acids after cocoa powder consumption in humans. J Agric Food Chem 58, 4706-4711.

38. Tzounis X, Rodriguez-Mateos A, Vulevic J, et al. (2010) Prebiotic evaluation of cocoa-derived flavanols in healthy humans by using a randomized, controlled, double-blind, crossover intervention study. Am J Clin Nutr 93, 62-72. 